\title{
Making Open Access Viable Economically
}

\author{
Andrew Hyde ${ }^{\star}$ (1), Russell A. Miller ${ }^{* *}$ and Emanuel V. Towfigh ${ }^{\star * *}$ (1)
}

\begin{abstract}
The Editors-in-Chief have decided that we will provide our much-cherished readers with an editorial every so often as a way of sharing insights from the "machine room" where so much of the thinking and work is done to publish the German Law Journal. We want to let you in on the ideas that are on our minds, share with you our observations, and include you in the conversations we are having that might be of interest to you. We begin this tradition with this issue, Volume 21 - Number 6. Andrew Hyde, a member of the editorial team with which the Journal has partnered at Cambridge University Press, as well as Russell A. Miller and Emanuel V. Towfigh, two of the Journal's co-Editors-in-Chief, open our From the Headquarters Essay with a piece on the Journal's experiences with and its further plans for making open-access (OA) publishing economically viable. Related to that theme, we also want to share news with you about the introduction of a voluntary article processing charge this fall. Finally, we want to draw your attention to a videos and podcasts service we will start to produce to accompany the scholarship published in the Journal as a way of promoting our authors' work and expanding access to their ideas. If you are interested only in these latter initiatives, you can also read the short section in the GLJ Instructions for Authors.
\end{abstract}

Keywords: Open Access; Funding; Multimedia; Law; German Law Journal

From its foundation over twenty years ago, the German Law Journal pioneered an innovative approach to legal scholarship, capitalizing on the Internet's new potential to disseminate scholarship widely without barriers to access. Founding editors Russell A. Miller and Peer C. Zumbansen launched the Journal in 2000 as an online-only, open access (OA) venue for transnational reflection on legal scholarship. The initiative resulted from the recognition that lawyers and scholars around the world increasingly were coming into contact with other laws and legal systems. Over the years, the Journal established itself as a leading journal in comparative, European and international law, whilst retaining its pioneering spirit-particularly through the publication of timely special thematic issues and scholarly reflections on important legal and constitutional events. It has been a forum for innovative research by diverse-and often earlycareer-legal scholars. Moreover, it bridged the best of two worlds-namely the United States tradition of a journal benefitting from the profound editorial contributions of a student editorial board, on the one hand, and the European and social science tradition of peer review, on the other hand. Today, members of the editorial board, representing a broad range of jurisdictions and subject-matters, are charged with assessing academic quality through a double-blind peer review mechanism, while the student editors at Washington \& Lee University School of Law in Virginia

\footnotetext{
${ }^{*}$ Andrew Hyde is a member of the editorial team at Cambridge University Press, Cambridge, United Kingdom.

${ }^{* *}$ Russel Miller is the J.B. Stombock Professor of Law at Washington \& Lee University School of Law in Lexington, Virginia, United States of America.

${ }^{* * *}$ Emanuel V. Towfigh holds the Chair in Public Law, Empirical Legal Research and Law \& Economics at EBS University Wiesbaden and is a Research Affiliate at the Max Planck Institute for Research on Collective Goods, Bonn, Germany. Contact: gljoutreach@cambridge.org.
} 
do the bulk of valuable, high-quality editorial work. The latter involves not only formatting and citation review, but also the ability for the students - as native English speakers-to contribute editorial feedback on substance, language and style-what we call "SLS" review.

Importantly, the Journal has always been free for readers to access and for authors to publish. That will always be the case. In this sense, the Journal has been an utterly democratic project. Everybody is free to access our content without subscription fees or paywalls that would obstruct the dissemination of research. And there is no fee for publishing, as has become the standard in the production of open-access content. For us, the resources to pay "processing fees" has never been and will never be determinative in deciding whether to publish cutting-edge scholarship. It is a good model and it expresses the Journal's core values. But it also has been challenging. Apart from occasional institutional grants or benevolent donors, the Journal has had to manage its work without reliable or extensive revenue.

The dynamic and ambitious development of the Journal, which coincided with the maturing of the OA movement in years past, made it apparent that the Journal would need to further professionalize to retain our place in the market by continuing to provide our authors with excellent service and our readers with excellent content. The Excel-based submission process and the manual type-setting needed upgrades, for example. The self-hosted Journal files deserved to be permanently and securely archived in a public repository. And the licensing agreements concluded with our authors had to be updated to comply with modern OA standards. Those efforts imposed demands on the editorial team that cut into the work needed to maintain the Journal's stringent review process, to curate content, and to be sure that the Journal was effectively represented in social media. The response to that tension has been to streamline some operative tasks and to seek to shift others to a trusted publishing team with experience in delivering these much-needed upgrades. This was the impetus for our search for a publishing partner that would lend profound professional competence in publishing the Journal without compromising our enduring and non-negotiable commitment to remain an open-access forum for the publication of excellent legal scholarship from a transnational perspective. This was the challenge: How to develop and grow while remaining free to readers and authors alike?

\section{How the GLJ and Cambridge Joined Forces}

Enter the not-for-profit Cambridge University Press. Cambridge is the world's oldest University Press, founded in 1534. Its journals' publishing program is much more recent and has been largely built around relationships with scholarly societies. It may be venerable, but Cambridge is able to adapt. As the momentum towards OA as the prevailing mode of scholarly publishing has grown, Cambridge has responded. Cambridge has formed policies that are compliant with research funders. And it has experimented, through the launch of OA titles and flipping journals to the OA model. With input from its publishing partners, Cambridge has contributed to debates about the sustainability and speed of change in the industry. Moreover, Cambridge has been at the forefront of debates as to how OA should be funded in Humanities and Social Sciences (HSS), especially in light of the very different ways in which knowledge is created and communicated in HSS by comparison with Science Technology Engineering and Medicine (STEM) fields. In recent years, Cambridge's commitment to openness has become bolder. Cambridge has embraced an exploration of open research principles; it has launched a platform for sharing early research outputs; and it has developed overarching Read \& Publish (R\&P) agreements with institutions that enable a wider range of affiliated authors to publish OA in Cambridge Journals.

\section{Reasons for the GLJ-Cambridge Collaboration}

Why was Cambridge drawn to publishing the GLJ? This is an easy question to answer, given Cambridge's enduring commitment to scholarly quality and the Journal's established reputation 
and standing in the discipline. For Cambridge, partnering with the GLJ was a chance to work with one of the best journals in the business. But Cambridge was also attracted to the creative challenge of publishing a successful OA journal in an HSS subject area. The opportunity for Cambridge to add value was clear. It could help upgrade and further professionalize the Journal's publishing process. But from the perspective of Cambridge, the partnership largely was inspired by the opportunity to work with the Journal's committed editors to find a long-term, stable basis for the Journal's operations.

What does the GLJ gain from publishing with Cambridge? Well, we were able to reach all goals described above in less than a year with Cambridge. And it has not cost the Journal its cherished independence or strained the Journal's enduring and non-negotiable commitment to remaining OA. Instead, the Journal gained a trusted and experienced publishing partner both dedicated to the Journal's long-term success and willing to lend its considerable editorial, marketing, production, and technology resources to securing the Journal's future. New functionality has been introduced since 2019: A professionalized publishing process; permanent identifiers (DOIs) to all articles; an online platform that is being actively developed in line with stakeholder expectations and changing standards; and long-term archiving arrangements (CLOCKSS). The Journal also benefits from Cambridge's participation in cross-industry initiatives for the good for scholarly publishing (such as COPE, CrossRef and OASPA).

\section{A Successful Joint Venture}

As readers may be aware, the Journal began this journey with Cambridge in 2019, a year that marked the GLJ's 20th Volume. The goals of the collaboration are to support the editorial team in the development of the Journal, to add new features, and to create a sustainable financial basis that keeps the Journal OA. That last ambition means that there will be no barriers to either reading or publishing content in the GLJ.

The fruits of our collaboration to date include a special 20th anniversary symposium on Populism and Constitutionalism — see the related issues GLJ 20.2 and 20.3. We have seen usage increase over the past eighteen months: At the time of writing, full-text views (in PDF or HTML) of the Journal's articles in 2020 average over 18,000 per month. Through Altmetrics we have been able to monitor the Journal's downstream impact, including the reference to Journal articles in some recent policy documents-for example, Michèle Finck's 2018 article Blockchains: Regulating the Unknown was mentioned in a 2020 report on blockchain from the Publications Office of the European Union, and Irene Wieczorek's 2015 GLJ article on national parliaments' subsidiarity arguments was referenced in a report last year from the European Public Prosecutor's Office.

\section{Introducing Videos and Podcasts}

In an effort to make the content of the Journal available to a broader public, including a readership increasingly native in and fluent with social-media and knowledge formats that depart from the written tradition, the editorial board has launched a video and podcasts series to accompany our published content. Editorial board members Nora Markard and Anna Katharina Mangold have taken the lead on this initiative, intertwining it with our social media efforts. We will present the first fruits of this exciting initiative in a few weeks' time! Authors with an accepted article are welcome to reach out to us if they are interested in adding this supplementary or "bonus material" to their publication.

\section{Let's Talk Money}

The partnership between the Journal and Cambridge has already been a huge academic success. But the challenge to make it viable economically remains a next step. To be clear, this is not a 
matter of seeking to make a profit from this venture, a venture which has always been first and foremost a labor of love inspired by shared values and ideals. The aim of our concern for revenue is to secure the sustainability of this joint effort because the developments and improvements we have outlined incur costs. To that end, a number of initiatives are either in train or about to get underway. These projects aim to develop a sustainable financial basis for the Journal's publishing over the long-term. Our innovative approach will be to combine support from people and organizations in the Journal's network with Cambridge's evolving OA models and wider trends for OA funding. But none of this will compromise our fundamental commitment to no barrier to access and no barrier to contribute.

Here are our ideas:

A voluntary article processing charge (V-APC). Beginning in October 2020, authors of articles accepted in the Journal who have access to grant or institutional funding for OA publication will be able to opt-in to pay a voluntary charge of $£ 1,000$ to contribute to the Journal's costs. There will be no obligation to do so, and importantly, the editorial decision to accept a manuscript for publication in the Journal will never consider whether or not such voluntary contribution can be made. We realize that many Journal authors will not be in a position to contribute financially in this way. That is okay. The introduction of this opt-in $V$-APC does not indicate a drift into a model of compulsory author charges. Rather, it is a way to support the Journal "community project," to support scholars who have fewer resources to fund the publication of their research, and to sustain the Journal financially in the long-term. This is and will remain a strictly voluntary gesture from our contributors who are able and willing to pay such a charge. The good faith with which we move in this direction also is signaled by the fact that the prescribed charge is rather modest when compared to typical OA article processing charges (APCs).

Read \& Publish. The Journal will be included in the overarching Read \& Publish agreements that Cambridge is forming with national library consortia, funding agencies, and university systems. These R\&P agreements aim to facilitate the transition to a more open scholarly publishing system in a sustainable way. Over thirty agreements have been formed and the number is growing. They include many of relevance to the Journal's author base, such as those with consortia in the Netherlands, Sweden, Austria, and Germany. These agreements are partnerships between participating institutions and Cambridge to redirect institutional funds to make OA publishing possible, including in subject areas where scholars do not generally have access to separate research grants. In most cases, the institutions that are part of Cambridge's R\&P agreements effectively cover the APC on behalf of their affiliated author, but in some cases, such as with the German DFG consortium, the APC is reduced. But to reiterate, the Journal's article processing charge is and will remain voluntary, so a DFG-affiliated author would only pay this reduced V-APC if she or he has the resources to do so.

Licensing. The Journal's content is included within platforms such as LexisNexis, ProQuest, Hein Online, Westlaw, and EBSCO, which help contribute small sums to the Journal's publishing costs.

Sponsorship, advertising and outreach. The Journal will begin to offer institutions within our natural orbit-universities, law firms, and online course providers- the opportunity to promote conferences, workshops, summer schools, and job opportunities. We also welcome parties to contact us if they are interested in sponsoring special, thematic issues that are selected under the Journal's independent editorial process.

\section{The Road Ahead}

Beginning in October 2020, authors will be asked whether they wish to opt-into the V-APC. This is independent of the editorial process and will not impact editorial decisions. If authors opt in, they will be taken through a separate payment process after acceptance, supported by Cambridge. If you are looking for further information, see the OA section of the GLJ Instructions for Authors. 
As you can tell from this Editorial, the Journal remains a vibrant, ever-developing platform. We invite you to send any questions about these initiatives or ideas to gljoutreach@cambridge.org. We look forward to engaging with you fully and reflecting publicly in further updates about our efforts to sustainably disseminate cutting-edge scholarship without any barriers for readers and authors. And we remain grateful for your trust and faithfulness in our shared project-a project and a community that has our authors, readers, and supporters at its center.

Thank you. 